\title{
MODEL DATA MINING DAN RASIO ALTMAN UNTUK PREDIKSI FINANCIAL DISTRESS PERUSAHAAN
}

\author{
Muksan Junaidi*, Ratna Dwi Rahayu \\ STT Ronggolawe Cepu, Blora Indonesia \\ muchsan.djunaedi@gmail.com \\ rdrcempaka@gmail.com
}

\begin{abstract}
ABSTRAK
Financial distress merupakan tahap atau situasi menurunannya kondisi keuangan perusahaan sebelum terjadinya kegagalan bisnis. Kegagalan ini berhubungan dengan likuidasi, dimana perusahaan gagal dalam menjalankan operasinya untuk mendapatkan laba. Metode prediksi financial distress sudah lama dikembangkan di bidang keuangan memakai Multiple Discriminant Analyst (MDA). Metode MDA yang paling banyak digunakan adalah rasio model Altman. Metode ini dipakai sebagai peringatan dini terhadap kondisi keuangan perusahaan. Penelitian ini bertujuan menganalisis algoritma data mining neuro fuzzy dengan data input dari rasio keuangan model altman untuk memprediksi financial distress perusahaan. Data penelitian dari website Bursa Efek Indonesia(BEI) di situs www.idx.co.id. Populasi data antara tahun 2012-2017 perusahaan emiten LQ45 sejumlah 80 perusahaan. Data awal dari laporan keuangan perusahaan dihitung dengan rasio Altman untuk mendapatkan nilai-nilai zscore tiga jenis kategori. Nilai-nilai ini disusun secara time series empat periode kebelakang yang nantinya sebagai data input algoritma neuro fuzzy model ANFIS. Langkah berikutnya pembentukan algoritma, training, testing, simulasi dan evaluasi model memakai application GUI dari program Matlab. Hasil dari model berupa nilai-nilai prediksi yang dibandingkan dengan hasil perhitungan rasio Altman tahun prediksi. Hasil akhir penelitian menunjukan, nilai prediksi model ANFIS dari fungsi keanggotaan Triangle terlihat sangat optimal, konsisten, dan efisien. Hal itu dibuktikan bahwa rata-rata nilai prediksi sebesar $9.95 \%$ mendekati nilai aktual tahun yang diperhitungkan, sedangkan hasil model ANFIS fungsi keanggotaan Trapesium, Gauss dan G-bell terlihat kurang optimal.
\end{abstract}

Kata Kunci: Financial Distress, Neuro Fuzzy, Prediksi, Rasio Altman.

\begin{abstract}
Financial distress is the stage or situation of a decline in the company's financial condition before a business failure occurs. This failure is related to liquidation, where the company fails to run its operations for profit. Financial distress prediction methods have been long developed in the field of finance using Multiple Discriminant Analyst (MDA). The most widely used MDA method is the Altman model ratio. This method is used as an early warning to the company's financial condition. This study aims to analyze the neuro fuzzy data mining algorithm with input data from the financial ratio of the Altman model to predict the company's financial distress. Research data are from the Indonesia Stock Exchange (IDX) website at www.idx.co.id. Data population between 2012-2017 LQ45 issuers are 80 companies. Preliminary data from the company's financial statements are calculated by Altman's ratio to get zscore values of three types of categories. These values are arranged in time series of four backward periods which will be used as input data for the neuro fuzzy algorithm ANFIS model. The next step is the formation of algorithms, training, testing, simulation and model evaluation using the GUI application from the Matlab program. The results of the model are predictive values that are compared with the results of the Altman ratio calculation of predicted years. The final results of the study show the predicted value of the ANFIS model of the Triangle membership function looks very optimal, consistent, and efficient. It was proven that the average predicted value of $9.95 \%$ was close to the actual value of the calculated year, while the results of the ANFIS model of the Trapezoid, Gauss and G-bell membership functions seemed less than optimal.
\end{abstract}

Keywords: Financial Distress, Neuro Fuzzy, Prediction, Altman Ratio. 


\section{PENDAHULUAN}

Badan Pusat Statistik(BPS) merilis bahwa, pertumbuhan ekonomi Indonesia selama 2017 mencapai 5,07\%. Meskipun tertinggi sejak 2014, realisasi ini meleset dari target APBN-P 2017 sebesar 5,2\%. (Kontan.co.id-Jakarta 5/2/2018). Dari data ini terlihat pertumbuhan industri manufaktur stagnan di 4,27\% dan porsinya juga anjlok $20,16 \%$ terhadap produk domestik bruto (PDB). Secara makro ekonomi global sedang bergerak naik, bahkan di wilayah Asean seperti Malaysia tumbuh 6,2\%, Thailand 4,3\%, Filipina 6,6\% dan Indonesia di angka 5\%. Indonesia secara optimal belum memanfaatkan peluang tersebut (Indef Bhima Yusdhistira 5/2/2018). Meski pertumbuhan ekonomi domestik dirilis lebih tinggi dari ekspektasi, tetapi hal tersebut tidak mampu menopang penguatan nilai tukar rupiah dan belum berdampak besar pada investasi pasar modal.

Rilis data Bursa Efek Indonesia(BEI), volume perdagangan naik, namun hargaharga saham cenderung turun, salah satunya saham Emiten LQ45. Data website IDX, (2016) indeks LQ45 menunjukan rata-rata harga saham penutupan turun 7,45\% menjadi $-33,79 \%$. Penyebabnya ekonomi makro, rasio pasar, dan internal dari rasio keuangan perusahaan : profitabilitas, likuiditas, leverage, aktifitas, dan rasio model lain seperti rasio model Altman.

Penelitian financial distress dengan rasio model Altman masih terbatas pada prediksi kesulitan keuangan satu tahun, sedangkan untuk prediksi beberapa tehun kedepan belum maksimal, untuk itu dibutuhkan metode lain dalam masalah ini. Metode data mining model neuro fuzzy masih jarang dimanfaatkan dibidang keuangan. Hasil prediksi metode ini sangat tergantung seberapa besar sumber data yang digunakan. Hasil prediksi ini sangat penting bagi pengelola perusahaan, investor dan kreditur digunakan untuk peringatan dini tentang kondisi keuangan perusahaan.

Penelitian model neuro-fuzzy ANFIS sangat menarik untuk dikembangkan, peneliti sebelumnya : Slamet Samsul Hidayat, dkk. (2013), tentang memprediksi pengguna bus trans Sarbagita dengan metode ANFIS. Indah Puspitasar, dkk.(2013) tentang "Model Selection in ANFIS by using Inference of $R$ Incremental for Time Series Forecasting". Rio Chaniago, dkk.(2014), tentang "Prediksi Cuaca Mengunakan Metode Case Base Reasoning dan ANFIS". Lala Nilawati, dkk. (2015), tentang "Penilaian Properti Menggunakan Metode ANFIS". Noor Azizah, (2016). tentang "Metode Adaptive Neuro Fuzzy Inference System untuk Prediksi Tingkat Layanan Jalan”. Herliyani Hasanah, dkk.(2017) tentang "Perancangan Aplikasi Sistem Cerdas untuk Prediksi Energi Listrik di PLTA Kedung Ombo". Hasil penelitian ANFIS mempunyai tingkat akurasi sangat baik, optimal, konsisten, fleksibel, stabil, efektif, dengan nilai kesalahan kecil.

Model ANFIS adalah sistem hybrid gabungan antara fuzzy inference system(FIS) dan jaringan syaraf tiruan (ANN) didalamnya terdapat model backpropagation (BPNN) untuk menghasilkan prediksi detail. Pengunaan ANFIS model inferensi fuzzy Tagaki-Sugeno-Kang(TSK) orde satu karena sederhana proses komputasinya. Keunggulan sistem ini dapat menterjemahkan pengetahuan para pakar berbentuk aturan rule pada fungsi keanggotaan. Atas dasar itu, penulis mengambil judul "Model Data Mining dan Rasio Altman untuk Prediksi Financial Distress Perusahaan”.

\section{Peramalan}


Peramalan adalah seni dan ilmu memperkirakan suatu even dimasa datang dengan pemrosesan data historis dan diproyeksikan untuk waktu akan datang melalui model matematis (Heizer dan Render ,2009:162-3). Metode peramalan dibagi dua : kualitatif (qualitative forecast) dan kuantitatif (quantitative forecast). Menurut Eddy Herjanto (2004:116), mengklasifikasikan peramalan berdasarkan horizon waktu masa depan yang melingkupinya. Peramalan kuantitatif dibagi dua jenis yaitu : Time Series Forecasting dan Associative Forecasting Method. Perhitungan kesalahan peramalan total digunakan deviasi mutlak rata-rata yaitu (Mean Absolute Deviation-MAD), dan kesalahan kuadrat rata-rata yaitu (Mean Squared Error-MSE), serta kesalahan persen mutlak rata-rata yaitu (Mean Absolute Percent Error-MAPE).

\section{Financial Distress Perusahaan}

Financial distress adalah kegagalan bisnis akibat kesulitan keuangan sangat parah sehingga perusahaan tidak mampu beroperasi dengan baik. Financial distress dapat terjadi jika jumlah kewajiban perusahaan melebihi nilai wajar aset atau ketika liabilitas lancar melebihi current assets. Financial distress adalah likuiditas sebagai awal dari kegagalan bisnis perusahaan. Rasio keuangan dapat digunakan sebagai indikasi adanya kebangkrutan di perusahaan (Toto, 2011:332).

Menurut Undang-undang No.4 tahun 1998 tentang kepailitan, dinyatakan bahwa kebangkrutan adalah situasi yang dinyatakan pailit oleh keputusan pengadilan. Kebangkrutan sebagai suatu kegagalan yang terjadi pada sebuah perusahaan diartikan sebagai kegagalan keuangan (Financial Distressed) (Brigham, 2001:2-3). Perusahaan mungkin mengalami kesulitan keuangan seperti kesulitan likuiditas (misal tidak bisa membayar gaji pegawai, bunga hutang, dll). Jika tidak diselesaikan, bisa berkembang menjadi kesulitan yang lebih besar, dan bisa sampai pada kebangkrutan (Mamduh, 2007:255).

Ketidakmampuan melunasi kewajiban menunjukkan kinerja negatif dan adanya masalah likuiditas. Didalam Munawir (2002:291) yang berkaitan dengan kesehatan keuangan dan potensi kebangkrutan perusahaan ada empat kategori:

a. Tidak kesulitan keuangan

b. Kesulitan keuangan tapi tidak pailit (bangkrut).

c. Tidak kesulitan keuangan tetapi kesulitan non keuangan dan diputuskan pailit.

Kesulitan keuangan dan jatuh pailit.

\section{Rasio Keuangan Model Altman}

Tahun 1968, Altman menerapkan multiple discriminant analysis (MDA) yaitu bentuk analisis diskriminan dari identifikasi rasio keuangan untuk model prediksi kegagalan bisnis perusahaan. Altman memakai lima rasio-rasio keuangan periode tiga tahun sebagai dasar analisanya. Nilai yang dihasilkan adalah nilai z-score sebagai klasifikasi kegagalan bisnis berdasarkan titik cut off dengan tiga kriteria yaitu : safe, gray dan distress (E.I.Altman,1999: A Revised Zscore Model).

Menurut (Lalith P. Samarakoon , dkk ,2003), model prediksi Altman mengalami beberapa revisi persamaan baru disesuaikan dengan perusahaan swasta dan tidak terbatas pada perusahaan manufaktur go public, Edward I.A. (Altman,1968-Z, 1983-Z' dan 1993-Z'), kemampuan tiga model z-score Altman dapat memprediksi kegagalan bisnis menggunakan laporan keuangan neraca dan laba(rugi). Menurut (Sanobar Anjum: 2012) Altman mengunakan lima rasio-rasio keuangan, 
yaitu : X1 $=$ working capital to total assets, $\mathrm{X} 2=$ retained earning to total assets, $\mathrm{X} 3=$ earning before interest and taxes to total assets, X4= market value of equity to book value of total debt, X5= sales to total assets. (Lalith P. Samarakoon, dkk ,2003) tiga model prediksi (Altman, 1968,1983, 1993) : Model tahun 1968, adalah $\mathrm{Z}=1.2 \mathrm{X} 1+1.4$ $\mathrm{X} 2+3.3 \mathrm{X} 3+0.6 \mathrm{X} 4+1.0 \mathrm{X} 5$.

Model yang dikenal sebagai (E.I.Altman, 1999: A revised z-score model) dengan fungsi diskriminan untuk perusahaan yang go public adalah : zona safe adalah nilai $\mathrm{Z}>2.99$, zona Gray nilai $\mathrm{Z}$ antara 1.80-2.99 dan zona distress nilai $Z<1.80$. Model ini pernah di terapkan untuk prediksi kegagalan bisnis pada U.S.Emergency Market (Altman, Hatzell dan Peck,1995), hasilnya di temukan $81 \%$ sukses pada model ketiga, didalam (Sanobar Anjum: 2012).

\section{Analisis Data Time Series}

Data time series adalah sekumpulan data berasal dari waktu ke waktu, seperti harian, mingguan, bulanan, kwartalan, tahunan dan dijadikan sebagai dasar untuk peramalan. Didalam (Ali Baroroh, 2013) Time Series merupakan data yang di catat, atau diamati dalam serangkaian tahapan waktu (Hanke, et all.2001). Kegunaan analisis ini untuk melihat perkembangan suatu objek yang di amati dan diteliti dari waktu ke waktu. Nilai data masa lalu hingga waktu ' $\boldsymbol{t}$ ' titik awal prediksi dan waktu prediksi ' $\boldsymbol{t}+\boldsymbol{p}$ '. untuk pemetaan dari titik ' $D$ ' sampai titik ' $\Delta$ ' secara terpisah dirumuskan :

$$
\mathrm{x}(t+p)=[x(t-(D-1) \Delta)] \ldots x(t-\Delta), x(t)
$$

\section{Algoritma Data Mining neuro-fuzzy}

Neuro-fuzzy adalah sistem inferensi fuzzy yang dilatih dengan algoritma pembelajaran turunan sistem neural network. Neuro-fuzzy salah satu hybrid system di soft computing untuk mendapatkan algoritma yang lebih sempurna (Kusumadewi, S., et al., 2006, p.4). Salah satu model neuro-fuzzy ANFIS diusulkan oleh (Roger Jang, 1993:667). Struktur ANFIS meliputi inferensi fuzzy model Takagi-Sugeno-Kang orde satu (Kusumadewi, S., et al., 2010 :379) seperti gambar berikut :

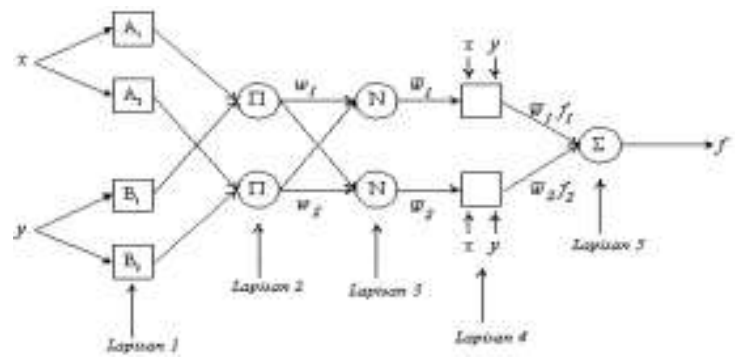

Gambar 1.1 Ilustrasi Struktur Sistem ANFIS

Layer-1: layer 1 setelah $x$ dan $y$. Setiap node i ke-I di layer ini adalah adaptive node dengan node fungsi ;

$O 1, i=\mu A i(x)$ untuk tiap $i=1,2$, atau

$O 1, i=\mu B i-2(y)$ untuk tiap $\mathrm{I}=3,4$

Fungsi anggotanya, generalize bell :

$O_{2, i}=w_{i}=\mu_{A i}(x) \times \mu_{B i}(y), i=1,2$

(4)

Dimana $\left\{a_{i}, b_{i}, c_{i}\right\}$ adalah parameter set.

Layer-2 : Tiap node layer adalah node yang tetap sebagai $\Pi$.

$O_{2, i}=w_{i}=\mu_{A i}(x) \times \mu_{B i}(y), i=1,2$

Layer-3 : Tiap node layer adalah node tetap sebagai $N$. Node ke - i mengkalkulasi rasio dari kekuatan rule ke - $i$.

$$
O_{3, i}=\overline{w_{l}}=\frac{w_{i}}{w_{1}+w_{2}} \quad, \quad i=1,2
$$

Layer 4: Tiap node i layer adalah node adaptif dengan node fungsi:

$\left.r_{i}\right)$

$$
O_{4, i}=\overline{w_{l}} f_{i}=\overline{w_{l}}\left(p_{i} x+q_{i} y+\right.
$$


Layer 5 : Node layer ini sebagai $\Sigma$, yang menghitung keluaran dari lapisan 4

$$
O_{5, i}=\sum \bar{w}_{\imath} f_{i}=\frac{\sum w_{i} f_{i}}{\sum w_{i}}
$$

\section{METODE PENELITIAN}

\section{Sumber Data, Populasi dan Sampel}

Penelitian menggunakan data sekunder dari website : http://www.idx.co.id. Data input dari laporan keuangan perusahaan emiten LQ45 di Bursa Efek Indonesia (BEI) tahun 2012-2017 sejumlah 80 perusahaan. Laporan keuangan konsolidasi perusahaan dipilih untuk proses perhitungan rasio-rasio model Altman untuk mendapatkan nilai zscore empat periode ke belakang secara time series. Sampel data berupa Sensus atau sampel jenuh, yaitu seluruh anggota populasi yang diamati semua. Periode amatan antara tahun 2012-2017.

\section{Langkah dan Perancangan Penelitian}

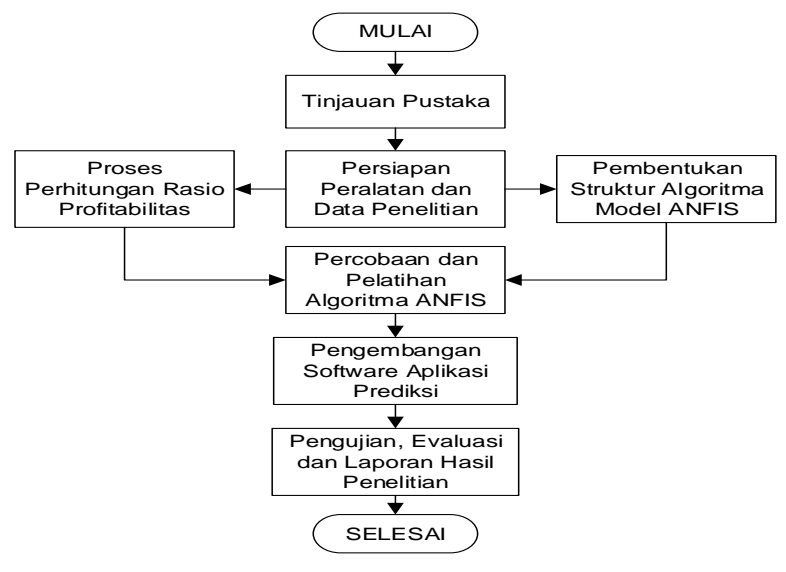

Gambar 2.1 Alir Perancangan Penelitian

1. Tinjauan Pustaka.

Bersumber dari prosiding, jurnal nasional dan internasional sesuai penelitian.

2. Persiapan Peralatan dan Data Penelitian. Peralatan Laptop dilengkapi developer Matlab. Data penelitian dari website www.idx.co.id emiten LQ45 di BEI tahun 2012-2017, sejumlah 80 perusahaan.

3. Pembentukan Struktur neuro-fuzzy ANFIS.

Pembentukan struktur ANFIS empat (4) MFs fungsi keanggotaan dari GUI Matlab : Segitiga, Trapesium, Gauss dan G-bell. Empat input data runtun waktu $\boldsymbol{x}(\boldsymbol{t}+\mathbf{p})$ yaitu kondisi $\mathrm{x}(\mathrm{t}-3), \mathrm{x}(\mathrm{t}-2), \mathrm{x}(\mathrm{t}-1), \mathrm{x}(\mathrm{t})$.

4. Perhitungan rasio keuangan model Altman.

Nilai zscore rasio model altman di proses dari laporan keuangan laba/rugi dan neraca perusahaan emiten LQ45.

5. Training dan Testing neuro fuzzy ANFIS. Training dan testing terhadap algoritma ANFIS memakai input data empat nilai zscore berbentuk time series, masa lalu sampai waktu " $t$ " adalah $\mathrm{x}(\mathrm{t}-3), \mathrm{x}(\mathrm{t}-2)$, $\mathrm{x}(\mathrm{t}-1), \mathrm{x}(\mathrm{t})$.

6. Pengembangan Aplikasi Prediksi.

Pengembangan aplikasi berbasis object oriented programming (OOP) dari Matlab dengan tahapan pekerjaan : analisa, desain, pemrograman dan testing model.

7. Pengujian, Evaluasi dan Laporan Hasil. Pengujian dan evaluasi model prediksi financial distress memakai input rasio altman melalui algoritma neuro fuzzy hasilnya sangat optimal dibandingkan dengan data atual dari hasil perhitungan rasio model altman.

\section{HASIL DAN PEMBAHASAN \\ Pengembangan dan Desain Aplikasi}

Pembuatan design aplikasi menggunakan tools box GUI dari program Matlab dalam menerapkan algoritma data mining neurofuzzy model ANFIS.

1. Pembentukan Struktur ANFIS 
Struktur ANFIS mempunyai empat masukan, yaitu kondisi $\mathrm{x}(\mathrm{t}-3), \mathrm{x}(\mathrm{t}-2), \mathrm{x}$ $(\mathrm{t}-1), \quad \mathrm{x}(\mathrm{t})$. Hasil struktur ANFIS 12 masukan fungsi keanggotaan dan 81 role berikut :

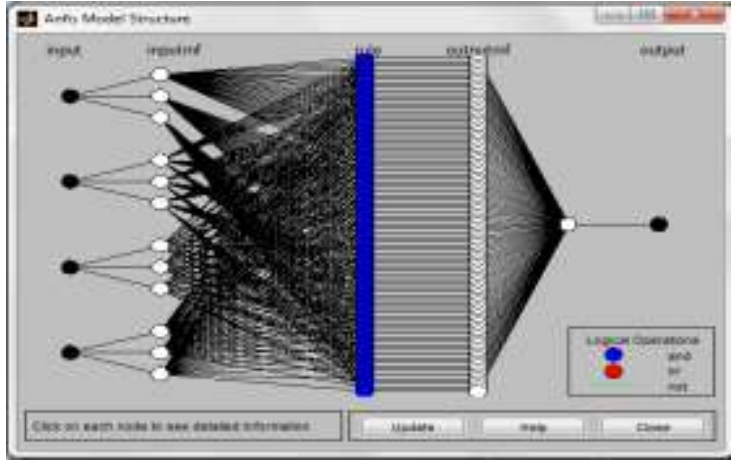

Gambar 3.1 Struktur ANFIS 4 input tiga kategori

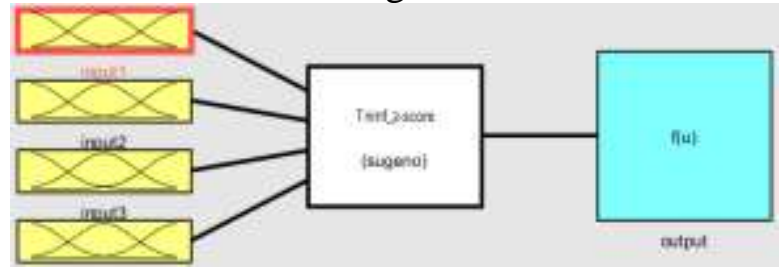

Gambar 3.2 Fuzzy Logic 4 inputs, 81 role sugeno dan 1 output

2. Percobaan dan Pelatihan Algoritma ANFIS

Mengunakan fungsi ANFISEDIT Matlab untuk menghasilkan ANFIS tipe Sugeno. Alir proses pembentukan dan pelatihan data berikut ini :

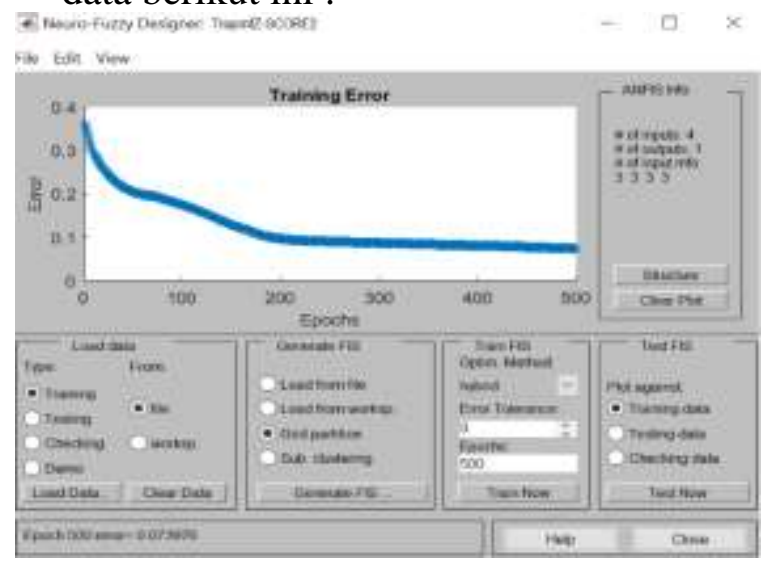

Gambar 3.3 Percobaan Data nilai zscore Altman untuk pembentukan struktur ANFIS
3. Input Data $A N F I S$

Data Input dibedakan tiga kondisi perusahaan (Distress, Grey dan Safe) dengan tiga kategori untuk fungsi keanggotaan Segitiga \& Trapesium:

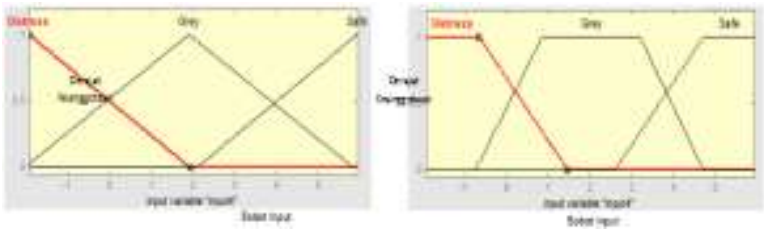

Dengan tiga kategori untuk fungsi keanggotaan Gauss \& G-bell :

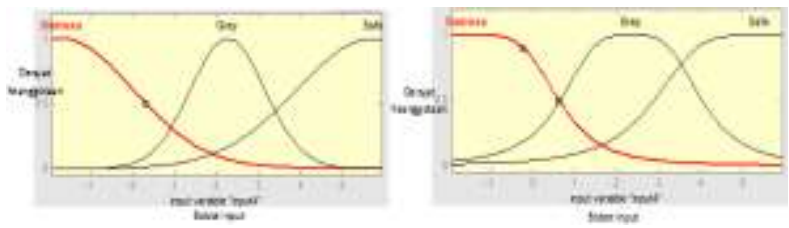

Gambar 3.4 Input ANFIS tiga kategori fungsi keanggotaan

4. Pengembangan dan Desain Aplikasi

Tampilan screen aplikasi yaitu menu program ,input $F I S$, data zscore altman time series kebelakang dari titik ' $t$ '. Dilengkapi dengan output keluaran nilai prediksi dan grafik prediksi seperti screen berikut ini :

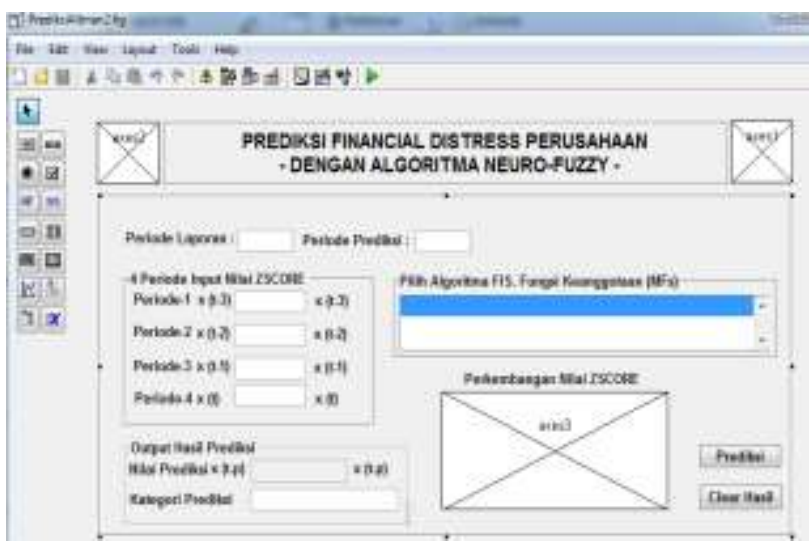

Gambar 3.5 Desain layar utama aplikasi prediksi

Testing dan Pengujian Aplikasi Prediksi 
Hasil pengujian aplikasi dengan tiga level area nilai prediksi financial distress perusahaan (Distress, Grey dan Safe) berikut ini :

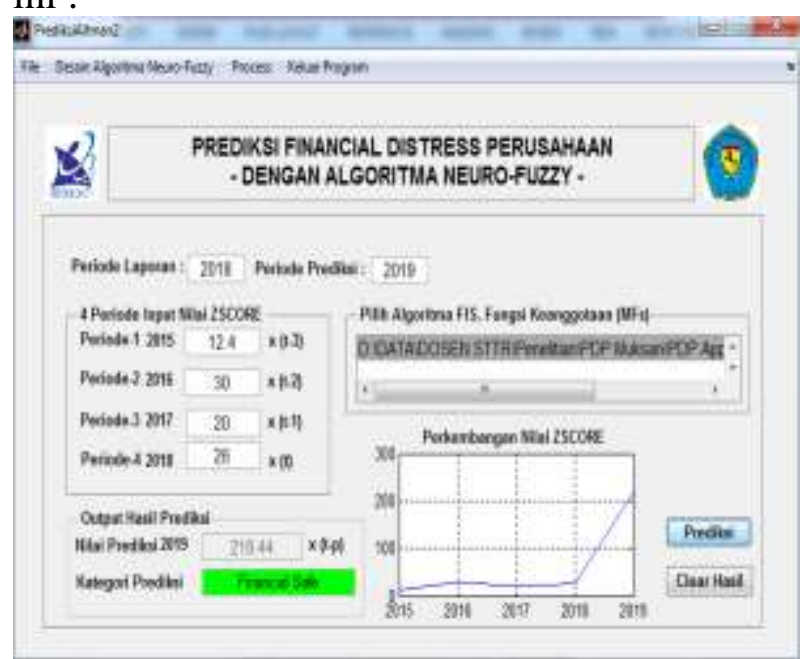

Gambar 3.6 Hasil Output Prediksi tiga kategori

\section{Analisa Hasil Prediksi}

Pembagian range nilai zscore pada area prediksi adalah berikut ini :

Tabel 3.1 Nilai zscore pada Area Prediksi

\begin{tabular}{c|c|} 
Zona & Nilai Z Score \\
\hline Safe & $>2.99$ \\
\hline Gray & $1.80-2.99$ \\
\hline Distress & $<1.80$ \\
\hline
\end{tabular}

Pada prediksi satu tahun kedepan dari titik “" tahun 2016 dan prediksi " $p=1$ " tahun 2017, maka $\boldsymbol{x}(\boldsymbol{t}+\mathbf{p})$ dari nilai-nilai masa lalu $=[\mathrm{x}(\mathrm{t}-3), \mathrm{x}(\mathrm{t}-2), \mathrm{x}(\mathrm{t}-1), \mathrm{x}(\mathrm{t}) ; \mathrm{x}$ $(\mathrm{t}+1)]$, maka input periodikalnya adalah tahun 2013,2014,2015, 2016. Didapat hasil rata-rata nilai zscore tahun $2017=9,95 \%$.
Perbandingan ZSCORE 2017 dan Hasil

\section{Prediksi 4 MFs}

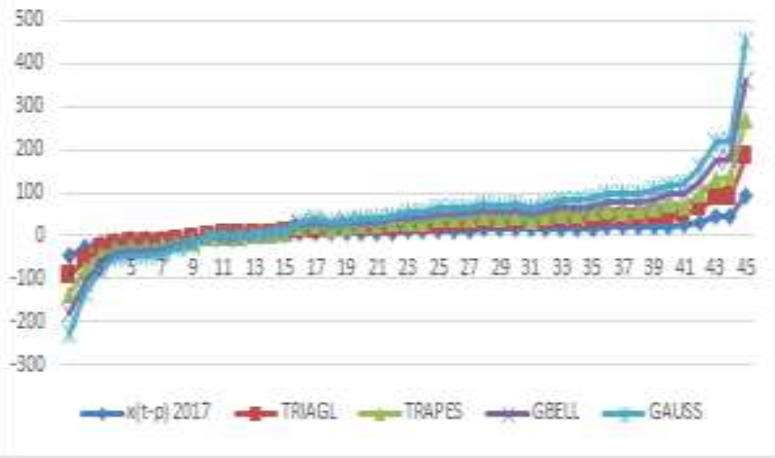

Gambar 3.7 Grafik perbandingan hasil prediksi 4 MFs dan nilai zscore 2017 Hasil rata-rata prediksi fungsi keanggotaan Trapesium $=9,71 \%$., Gauss $=9,93 \%$. dan G-bell $=9,88 \%$ kurang optimal, sedangkan rata-rata nilai prediksi fungsi keanggotaan Segitiga dengan tiga kategori input hasilnya optimal, yaitu: 9,95\%.

\section{PENUTUP}

Aplikasi prediksi financial distress model ANFIS memakai empat fungsi keanggotaan dan data input tiga kategori. Pada fungsi keanggotaan Trapesium, Gauss dan Generalized bell hasilnya kurang optimal, sedangkan fungsi keanggotaan segitiga hasilnya paling optimal dan sangat konsisten dengan rata-rata nilai zscore tahun 2017 sebesar 9.95\%. Untuk prediksi financial distress satu tahun kedepan paling optimal mengunakan model ANFIS fungsi keanggotaan Segitiga. Jadi aplikasi prediksi dengan algoritma model ANFIS hasilnya sangat optimal $100 \%$ lebih terinci, konsisten, dan sangat baik. 


\section{DAFTAR PUSTAKA}

Abdul Kadir,"Analisis Faktor-Faktor Yang Mempengaruhi Kebijakan Dividen Pada Perusahaan Credit Agencies Go Public di (BEI)“. Jurnal Manajement Akuntansi Volume 11, No.1,(2010).

Ali Baroroh, 2013. "Analisis Multivariate dan Time Series dengan SPSS 21", Penerbit PT. Elex Media Komputindo; Kompas Gramedia, ISBN:978-6020220-65-9.

Brigham, Eugene dan Joel F Houston. 2001. Manajemen Keuangan II. Jakarta: Salemba Empat.

Eddy Herjanto, (2007). Manajemen Operasi, Penulis Edisi Ketiga. Jakarta: PT Raja Grasindo Persada.

Edward I. Altman (1999), Predicting Financial Distress of Companies; Revisiting the Z-Score and ZETA Models*.

Heizer, Jay \& Barry Render. 2009. 8th ed. Operation Management. Upper Saddle River, New Jersey : Prentice Hall.

Herliyani Hasanah, Nurmalitasari, 2017."Perancangan Aplikasi Sistem Cerdas untuk Prediksi Energi Listrik Pemakaian Sendiri di PT Indonesia Power Sub Unit PLTA Kabupaten Wonogiri”. Prosiding SNATIF Ke-4
Tahun 2017, ISBN: 978-602-1180-501.STMIK Duta Bangsa Surakarta.

Indah Puspitasari, Brodjol Sutijo S U dan Suhartono, 2013. "Model Selection in Adaptive Neuro Fuzzy Inference System (ANFIS) by using Inference of $R$ Incremental for Time Series Forecasting ", International Journal (IJSR), India Online, Vol 2, Issue 2, ISSN: 2319-7064.

J.-SR Jang, 1993. "ANFIS: AdaptiveNetwork-based Fuzzy Inference Systems", IEEE Transactions on Systems, Man, and Cybernetics, Vol.23, No.3, p 665-685.

Kusumadewi, Sri dan Sri Hartati, 2010. Neuro-Fuzzy (Integrasi Sistem Fuzzy dan Jaringan Syaraf). Edisi-2. Yogyakarta: Graha Ilmu.

Kusumadewi, Sri, 2003. Artificial Intelegence (Teknik dan Aplikasi)". Yogyakarta: Graha Ilmu.

Lala Nilawati, Mochamad Wahyudi, 2015."Penilaian Properti Menggunakan Metode ANFIS", Konferensi Nasional Ilmu Pengetahuan dan Teknologi (KNIT) 2015, 8 Agustus 2015, Bekasi, ISBN 978-602-72850-0-2.

Lalith P. Samarakoon, et al.(Fall 2003), “Altman's Z-Score Models of Predicting Corporate Distress : Evidence from the Emerging Sri 
Lankan Stock Market” ,Edition Joournal of the Academy of Finance at the University of St. Paul.

Munawir, Slamet (2002),Akuntansi

Keuangan dan Manajemen, Edisi

Pertama. Yogyakarta: BPFE.

Noor Azizah, 2016. "Metode Adaptive Neuro Fuzzy Inference System (ANFIS) untuk Prediksi Tingkat Layanan Jalan". Jurnal DISPROTEK Vol 7. No.1 Jan 2016. Fakultas Sains dan Teknologi, UNISNU Jepara.

Rio Chaniago, The Houw Liong, dan Ken Ratri Retno Wardani. 2014, "Prediksi Cuaca Mengunakan Metode Case Base Reasoning dan Adaptive Neuro Fuzzy Inference System". Jurnal Informatika, Vol. 12, No. 2, November 2014, 90-95. ISSN 14110105. DOI: 10.9744

Slamet Samsul Hidayat, I Putu Eka Nila Kencana dan Ketut Jayanegara, 2013. "Prediksi Pengguna Bus Trans
SARBAGITA dengan Metode Adaftive Neuro Fuzzy Inference System",Edisi E-Jurnal Matematika Vol.2, No.3, Agustus 2013, Hal 46-52, ISSN: 23031751.

Syamsudin, Lukman, 2007. "Manajemen keuangan perusahaan". Jakarta: Raja Grafindo Persada.

Takagi,T., and M.Sugeno, 1985. "Fuzzy identification of systems and its application to modeling and control". IEEE Transactions on Systems, Man, and Cybernetics ,Vol SMC-15, No.1:116-132.

Toto, Prihadi. 2011. Analisis Laporan Keuangan Teori dan Aplikasi. Jakarta: PPM.

website IDX ; http://www.idx.co.id website Indef Bhima Yusdhistira 5/2/2018

website Kompas ; http://www.kompas.com. website Kontan.co.id-Jakarta, 5/2/2018 